\title{
On Morris's Mechanisms
}

\author{
Donald M. Baer \\ University of Kansas
}

My colleague Edward Morris (1993) has produced another piece of careful, comprehensive, relevant scholarship and conceptual analysis. My admiration for it has been shaped from great to greater, because I have also heard him expound it often: once to our department proseminar, and once to $\mathrm{ABA}$; and parts of it several times to the seminar he and $I$ and various of our colleagues have conducted for so many years, and parts of it sometimes to me. So I have heard him defend it often, sometimes against me; I know how strong an argument it is. Furthermore, after his department proseminar, my own students spent their next meeting with me dissecting it (as assigned), and $I$ defended it (sometimes), teaching me even better how strong it is.

His argument has changed my behavior; I no longer call myself a mechanist. (However, none of my other science strategies has changed.) I see now that mechanism has gained so many meanings since I first learned it in a 1949 philosophy class, and meanings of such divergence, that in effect it no longer has any dependable meaning at all, short of several hours spent defining terms and establishing values every time I discuss it with a new colleague, and so I will stop using it.

Perhaps the term was always that undependable; perhaps my philosophy class was deficient in displaying the variety of its meanings. But perhaps not. Consider an analogue, feminism. I used to know what feminism was, I thought; it was the insistence on completely equal opportunity for women to have, and to refuse to have, just as good and bad an existence as men have had, and have refused to have, all this time (biological impossi-

Correspondence concerning this article should be sent to D. M. Baer, Department of Human Development, University of Kansas, Lawrence, KS 66045 2133. bilities excepted). Then I heard portions of the Republican National Convention, and learned that feminism was something quite, quite different. However, a little deconstruction suggested a new proposition: The Convention's feminism was not feminism: it was simply what they wanted to run against. Their version of feminism looked profitable to run against.

Whether that deconstruction is accurate or not, the next scholar searching the literature of feminism will be obliged by intellectual integrity to include the widely publicized Republican version. There goes feminism; those of us who want to be understood might as well abandon the word, leaving it to those who understandably do not want to be understood. That leads me to ask if perhaps the new mechanisms that so many philosophers and essayists have defined, which often seem incompatible with the mechanism I had learned, was perhaps not really mechanism, but simply what those philosophers and essayists wanted to run against? Have we not all heard the behaviorism we know redefined into a distasteful diversity of things that its dislikers will find easier to teach and preach against? And are scholars not obliged to treat that created diversity seriously?

Indeed, the list of somethingisms that have gone the same path of imposed ambiguation may be very, very long. Furthermore, some of us have helped do it to some of them: How often do we casually redefine cognitive science or psychoanalysis into a convenient foil, rather than read the thousands of pages necessary to know clearly what they think it is? (When we explain away naive criticisms of radical behaviorism, we cite, eventually, thousands of pages that we have read and the critics have not. Is it not likely that the same price prevails in the opposite direction?)

The loss of mechanism is tolerable for 
me today, because its inevitable long-ago heritage for me was a set of proof strategies, and they do not disappear, not even with the ambiguation of their parent term. The mechanism I learned required some particular choices among the diverse canons of proof-a diversity displayed much more thoroughly to me in philosophy classes than in science classes. Mechanism seemed to require the set called natural science. I did not prove that it was the best set; proof is something that you can do after you have chosen your canon of proof, not before. Consequently, I am irrationally devoted to certain standards of measurement and of experimental design; the statements that I consider certain and valuable are the ones that meet those standards, which I consider the standards of proof; all other statements I call definitions, tautologies, assumptions, presumptions, or game playing (and when they are organized well enough, conceptual analysis), and I consider them not as valuable - not proven.

Thus, I am not greatly interested if anyone presumes that behavior is ultimately explainable in physical and chemical terms, or if they presume that it is not. The thesis that it is is a matter for proof; I will be greatly interested only when the proof is presented (if I can understand it). Similarly, I am not greatly interested if anyone presumes that a behavior and its causes are in such constant interaction that each is simultaneously cause and effect of the other, and then concludes that this destroys the very concepts of cause and effect, or demotes them to helpless linearity. I will be greatly interested in a proof that A can cause B, and in a proof that B can cause A. I can also see the plausibility of each doing so simultaneously, but plausibility is not worth much to me, compared to proof; I would be greatly interested in a proof, and meanwhile my interest will remain casual.

That is something of what it is like to be what I used to call a mechanist, before the term went away. Terms come and go; but a good canon of proof is something to keep.

\section{REFERENCE}

Morris, E. K. (1993). Behavior analysis and mechanism: One is not the other. The Behavior Analyst, 16, 25-43. 